\title{
RisK MANAGEMENT IN ACCREDITED TESTING LABORATORIES
}

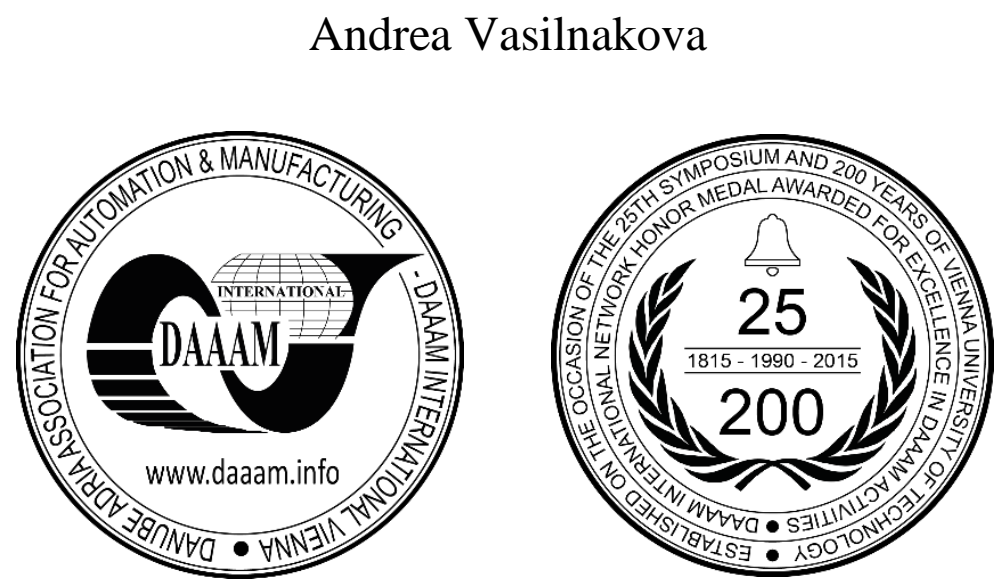

This Publication has to be referred as: Vasilnakova, A[ndrea] (2018). Risk Management in Accredited Testing Laboratories, Proceedings of the 29th DAAAM International Symposium, pp.1071-1075, B. Katalinic (Ed.), Published by DAAAM International, ISBN 978-3-902734-20-4, ISSN 1726-9679, Vienna, Austria

DOI: $10.2507 / 29$ th.daaam.proceedings. 153

\begin{abstract}
The accuracy and reliability of laboratory tests play an important role in decision-making in the field of industry and services. These tests depend, in particular, on pre-analytical, analytical and post-analytical phases, and it is, therefore, unnecessary the related processes in detail and to know how to manage them. It is therefore recommended to comply with the requirements of ISO 17025:2017 and the use of risk management tools and procedures. The paper has a conceptual nature and summarizes the information from the literature, specifying the most common mistakes that occur in the various phases of testing.
\end{abstract}

Keywords: calibration; errors; testing; laboratory; risk management

\section{Introduction}

Calibration as well as testing and sample analysis is the daily practice of more than 60,000 laboratories around the world. Their main goal is to assure customers of the reliability of their results. It enables them to demonstrate that they are technically competent and able to produce valid and reliable results [1].

It is very important to perform a number of quality control tests before and also during different stages of processing [2]. In accredited testing laboratories, accredited tests of products from different areas of the industrial sphere are performed to verify their compliance with the legal and customer's requirements.

The problem is that not all laboratory tests will achieve successful results due to various errors, which may occur in the pre-analytical, analytical and postanalytic phases [3]. To obtain reliable test results, prevention and complete error detection is required in all steps [4]. Each stage and specific activity in the laboratory are subject to various risks. The risk realtes to the unknown outcomes of the future event with the assumption that these outcomes will be undesirable. "To deal with it effectively, risk-based considerations must be integrated into an analytical framework such as Risk Management" [5]. The ultimate goal of any risk management process is to identify, assess, mitigate, and eliminate the risks to an acceptable level [5]. The prerequisite of a safe and competent laboratory is its management by managers who are able to apply the theory of risk and to reduce it to an acceptable level. Each laboratory must firstly assess the possible occurrence of errors and outline the steps necessary for their detection and prevention before they may cause to any undesirable event [6]. 
This can be achieved by risk management in accordance with the requirements of the standard ISO 17025:2017. Risk management is currently a decisive function, it is more than just a simple process of hazard avoidance. The company Marsh helps organizations create or revise existing risk management frameworks and implement other procedures to help organizations achieve better results [7]. The purpose of this article is to present risk management possibilities related to standard ISO 17025:2017 in accredited testing laboratories.

\section{Risk and management of risk in laboratories}

According to the standard ISO 31000:2018, the risk is defined as the deviation from the expected. It may be positive or negative [8]. The risk arises in every activity, because no one knows exactly what will happen in the future. If we knew how to predict what will happen with absolute accuracy, there would be no risk. Cechova defines risk as a situation where there is a probability of a negative deviation from the desired.

Risk can be expressed as the possibility of gain or loss. [9]. Stoneburner et al. define risk as the "net negative impact of the exercise of a vulnerability, considering both the probability and the impact of the occurrence" [10]. Nichols defines risk as a probability of a laboratory error that could lead to an undesirable event [11]. One of the risks of a testing laboratory is also failure to meet customer's requirements, delivering of incorrect analytical results to customer, and failure to meet the requirements of accreditation. All this may damage the reputation of the laboratory [12].

Risk management is defined as coordinated activities of control and review of the organisation regarding the risk [8]. Risk management is to be understood as part of the organization's quality management system. Nichols defines risk management as a method of determining relationships in processes of identifying, analyzing, evaluating, handling, reducing and continuous monitoring of risks that helps to minimize losses and maximize opportunities, keeping risks at an acceptable level [11].

Risk management is currently one of the main topics of interest to researchers and workers in the field of management [13]. Studies offer several variants of risk management. Boehm has proposed a variant that consists of two main phases: the first stage is the risk assessment, which involves identification, analysis, prioritization, and the second control phase, which involves risk management planning, categorization and monitoring [14].

Kremljak describe a process consisting of four phases - planning, assessment, handling and monitoring. This process coincides with the Deming cycle of continuous improvements in quality management (PDCA - Plan, Do, Check, Act) [15].

Chapman and Ward have proposed a process consisting of nine phases [16]:

- Defining the key aspects of the project,

- Focusing on a strategic approach to risk management,

- Identifying possible risk locations,

- Structuring information about risk assumptions and relationships,

- Assigning ownership and responsibility for a given risk,

- Estimating the extent of uncertainty,

- Evaluating the relative magnitude of the different risks,

- Assigning responsibilities for planning, monitoring, and control of the risk.

Risk management involves three basic phases:

- Identification of risks

- Assessment of risks

- Mitigation of risks

This short survey highlights the existence of compliance in the area of risk management.

\subsection{Identification of risks}

Identification of risks is the basic phase in risk management practice. Identifying, we record the risks that can affect the whole activity of the laboratory. This step is critical to effective risk management throughout the process. The outputs from identification of risks are further used as input for risk analysis. This is a recurrent process that must be thorough to ensure that all threatening risks are accurately identified. Identification consists of systematic identification, analysis, categorization and documentation of risks [17].

Risk identification is the most difficult step in the risk management process. Therefore, it is important for the laboratory to focus on creating a comprehensive register of risks. The goal is to identify all risks before they occur [18]. 


\subsection{Risk assessment}

The risk assessment and determination of its weight is necessary for selection of the appropriate measure depending on the situation that the risk may cause. The studies have shown that $46 \%$ to $68.2 \%$ of laboratory errors occur in the pre-analytical phase [19]. The pre-analytical phase represents all the processes, processes and analyzes performed until the sample is received by the laboratory [19]. This phase of the testing process is responsible for most laboratory errors, involving problems with manipulation with samples that occur before the samples arrive to the laboratory. Serious mistakes may occur during transportation, manipulation and identification of samples. The pre-analytical phase must therefore include strict control measures to avoid problems [20].

Errors that may occur in the pre-analytical phase are: inappropriate test requirements, errors during order placemet, use of incorrect containers, inadequate sampling and sample transportation, inappropriate sample volume, sorting and labeling errors [21]. As reported by Carraro et al. the most common mistakes in the pre-analytical phase are: missing sample, lost application for sample testing, incorrect or missing sample identification, contamination, insufficient sample size, inappropriate packaging, inappropriate shipping and storage conditions [22]. The majority of errors in the entire testing process come from a pre-analytical phase that takes place outside of the laboratory and is closely related to communication between the laboratory and the the customer. It is therefore advisable to focus the effort of risk reduction at this stage, thereby maximizing the reliability in the entire testing process. The second phase is the analytical phase. Unlike the pre-analytical phase, approximately $7 \%$ to $13 \%$ of laboratory errors occur in the analytical phase. This phase includes what is commonly considered "the real" laboratory testing or diagnostic procedures which eventually produce results. Errors that may occur in the analytical phase are: equipment and instrument failure, failure in quality control, incorrect test or calibration procedure [23]. In addition, according to the requirements of ISO 17025 , it is necessary to manage the risks associated with the occurrence of errors, such as: inadequate environmental conditions, inappropriately chosen testing method, loss of the sample or the measure, incorrect estimation of uncertainty of measurement, incorrect identification of components of uncertainty, absence of traceability to the units of SI and other risks resulting from non-compliance with the requirements for the management of the laboratory [24].

In the post-analytical phase occurs $18.5 \%$ to $47 \%$ of errors. The post-analytical activities within the laboratory include: verification of the results, their processing in the information system and communication with clients [25]. There are studies that analyze the tasks performed at each stage of the test from the pre-pre-analytical to the post-postanalytical phase. As Piton states, the most common errors in the overall testing process of the laboratories are as follows:

- Pre-pre-analytical phase (46\% - $68 \%$ ) - inappropriate test application, incorrect ordering, incorrect sample identification, incorrect sampling, inappropriate shipping container, improper handling, storage or shipping.

- Pre-analytical phase (3\% - 5\%) - incorrect sorting and dispatching of samples, sample labelling.

- Analytical phase (7\%-13\%) - device failure, mixing of the samples, unspecified quality control failure.

- Post-analytical phase (13\% - $20 \%$ ) - incorrect verification of analytical data, failure in reporting, poor handling, incorrect data entry, failure or delay in reporting of critical values.

- Post-post-analytic phase (25\% - $46 \%$ ) - delayed or missed response to laboratory reports, misinterpretation of the results, inappropriate or inadequate corrective action plan, failure to provide na appropriate consultation [26].

Based on presented views of the authors, figure 1 lists the likely failures in the individual phases of laboratory testing.

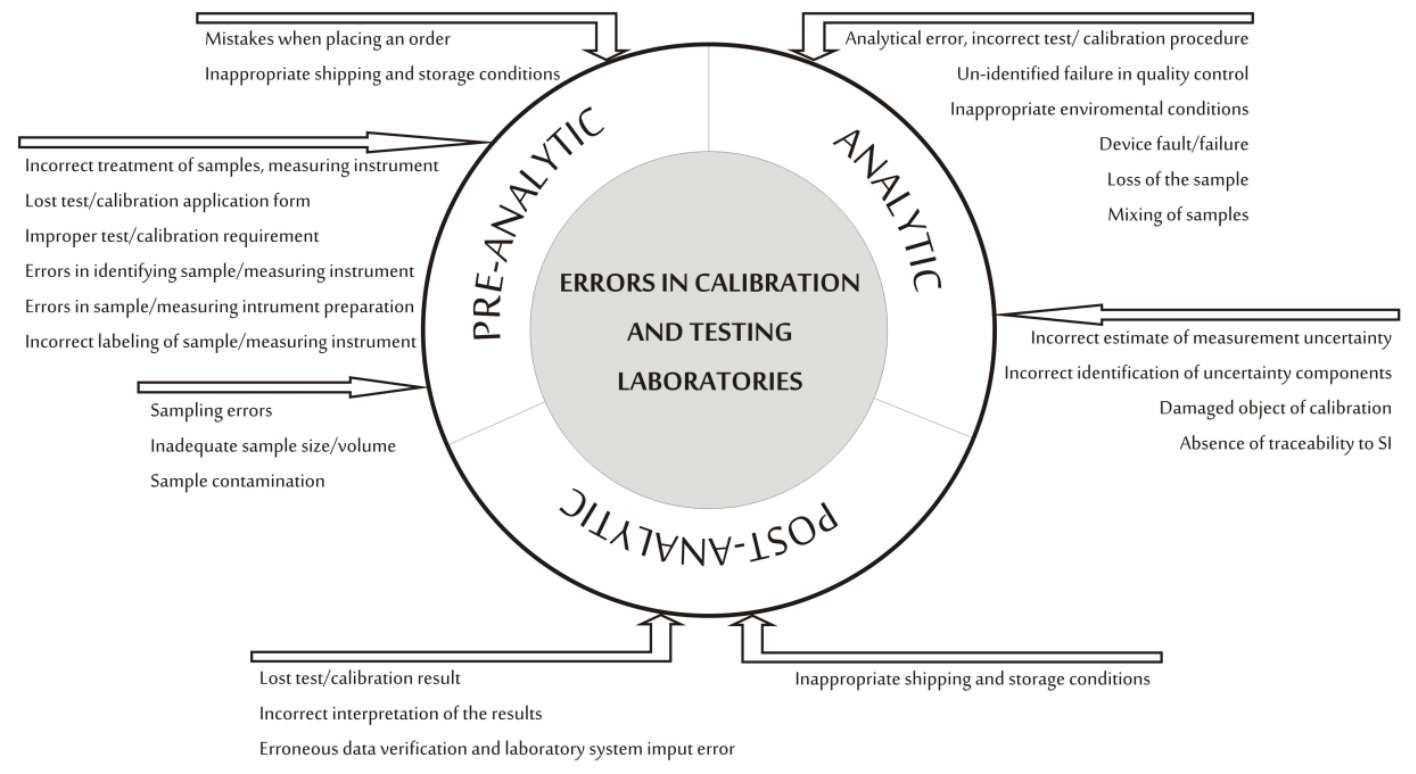

Fig. 1. Summary of the most common failures in the laboratory 


\subsection{Mitigation risks}

The success of every effort to reduce failures must be monitored to assess the effectiveness of the measures taken. The established quality indicators (number of complaints, number of calibrations, etc.) must be used for the assessment. It is extremely important to integrate into the testing process the areas involving non-expert staff, departmental communication and overall collaboration. Therefore, the entire system must be involved in improving the overall testing process. Appropriate and effective staff training must be ensured throughout the organization in order to be able to carry out processes in compliance with ISO requirements [23].

The development and extensive implementation of a comprehensive quality management system (QMS) is the most effective strategy to minimize uncertainties in laboratory diagnostics. This can be pragmatically achieved by using three complementary steps: to prevent undesirable events (error prevention), to make them more visible (error detection) and to mitigate their adverse consequences if they occur (error management) [27].

A common tool for identification of causal factors and interpreting their relationship to a defined risk is the risk analysis tool (Ishikawa diagram) This graphical risk analysis tool enables employees to visualize and classify causal factors that may contribute to failure. With this tool, the causes of the risks can be moderated or managed by applying a laboratory's Individual Quality Control Plan (IQCP).

Risks identified through the risk analysis tool can be further analyzed using the FMEA - Failure Mode and Effect Analysis. It uses a systematic process of identifying potential failures before they occur in order to eliminate or minimize risk. A similar technique for examining probable sources of failure is Fault Tree Analysis (FTA). The FTA is a top-down approach that begins with the assumption of a high level of danger and the identification of the main cause of the hazard. It is useful in the case of possible multiple malfunctions and their effects at the system level [28].

\section{Conclusion}

The paper presents a literature review of risk management options in accredited testing laboratories related to standard ISO 17025:2017. The review suggests that the laboratory testing process is carried out in three phases and that in each phase the individual operations are subject to various risks that may give rise to errors. Therefore, it is necessary for the laboratory to implement risk management into its activities. With the help of risk management techniques, we minimize the possibility of errors, thus we can ensure the capability of laboratory test results. Risk management does not provide for complete risk elimination, but by introducing a rigorous management process that involves detailed identification, classification, analysis, and monitoring of risks, we will contribute to reducing the risk to an acceptable level. The review also shows that the decisive phase of laboratory testing is the pre-analytical phase. Therefore, the laboratory should focus on this phase.

The laboratory can use a variety of analytical tools and methods to thoroughly identify the causes of risk. The examples of such tools include: Failure Modes and Effects Analysis (FMEA), Fault Tree Analysis (FTA), Event Tree Analysis (ETA), Risk Project Analysis (RIPRAN), Risk Matrix, and the like. Using these methods, laboratories can work effectively with the risks and thus increase the chance of achieving the accreditation by demonstrating that they are technically competent and able to produce valid and reliable results. Further research will be focused on the use of this tools and methods, and together with risk management, specific experiments will be carried out in accredited testing laboratory.

\section{Acknowledgments}

This paper was developed within the project VEGA 1/0904/16 "The utilization of processes capability and performance and products dimensional tolerances in the management of material consumption and related economic, energy and environmental consequences (MINIMAX-3E)" supported by The Ministry of Education, Science, Research and Sport of the Slovak Republic.

\section{References}

[1] Tranchard, S. (2017). ISO/IEC 17025 - moves to final stage of revision, 2017. Available from: https://www.iso.org/news/ref2212.html, Accessed: 2017-06-06.

[2] Sharaki, O.; Abouzeid, A.; Hossam, N. \& Elsherif, Y. (2014). Self assessment of pre, intra and post analytical errors of urine analysis in Clinical Chemistry Laboratory of Alexandria Main University Hospital. Saudi Journal for Health Sciences, Vol. 2, No. 3, 2014, pp. 96-102, DOI: 10.4103/2278-0521.134863.

[3] Çuhadar, S. (2013). Preanalytical variables and factors that interfere with the biochemical parameters: a review. The Journal of Physiology and Biochemistry 2013, Vol. 2, No. 2, 2013, pp. 1-7, Available from: http://www.oapublishinglondon.com/images/article/pdf/1384883561.pdf.

[4] Neogi, S. S.; Mehndiratta, M.; Gupta, S. \& Puri, D. (2016). Pre-analytical phase in clinical chemistry laboratory. Clin Sci Res, 2016, pp. 171-178, DOI: 10.15380/2277-5706.JCSR.15.062.

[5] Lemos, D. T. \& Almeida, D. L. T. (2001). Whole Life Cycle Risk Management. Assessment and Management of Environmental Risks 2001, 4, pp. 401-407, DOI: https://doi.org/10.1007/978-94-010-0987-4_44. 
[6] Mortimer, S. T. \& Mortimer, D. (2015). Quality and Risk Management in the IVF Laboratory, 2nd ed.; Cambridge University Press: United Kingdom, 2015.

[7] Marsh. (2018). Management, Risk Management Optimization, 2018. Available from: https://www.marsh.com/us/services/marsh-risk-consulting/risk-management-optimization.html.

[8] International Organization for Standardization. (2018). ISO 31000. Risk Management - Guidelines, ISO, 2nd ed., Geneva, Switzerland. 2018.

[9] Cechova, L. \& Simon. M. (2011). Risk Management in view of the product lifecycle, Proceedings of the 22st International DAAAM Symposium, Vienna, ISSN 1726-9679, ISBN 978-3-901509-83-4, Katalinic, B. (Ed.), 0725, Published by DAAAM International, Vienna, http://www.daaam.info/Downloads/Pdfs/proceedings/proceedings_2011/0725_Cechova.pdf

[10] Stoneburner, G.; Goguen, A. \& Feringa. (2002). A. Risk Management Guide for Information Technology Systems; Gaithersburg, 2002, DOI: http://dx.doi.org/10.6028/NIST.SP.800-30r1.

[11] Nichols, H. J. (2011). Laboratory Quality Control Based on Risk Management. Annals of Saudi Medicine 2011, Vol. 31, No. 3, pp. 223-228, DOI: 10.4103/0256-4947.81526.

[12] Wong, S. (2017). Risk-based thinking for chemical testing. Accreditation and Quality Assurance 2017, Vol.22, No. 2, pp. 103-108, DOI: 10.1007/s00769-017-1256-X.

[13] Raz, T. \& Michael, E. (2001). Use and benefits of tools for project risk management. International Journal of Project Management 2001, Vol. 19, No. 1, pp. 9-17, DOI: https://doi.org/10.1016/S0263-7863(99)00036-8.

[14] Boehm, W. B. (1991). Software Risk Management: Principles nad Practices. IEEE Software 1991, Vol.8, No.1, pp. 34-35, DOI: 10.1109/52.62930.

[15] Kremljak, Z. (2010). Risk Management, Proceedings of the 21st International DAAAM Symposium, Vienna, ISSN 1726-9679, ISBN 978-3-901509-73-5, Katalinic, B. (Ed.), 127, Published by DAAAM International, Vienna,Austria, http://www.daaam.info/Downloads/Pdfs/proceedings/proceedings_2010/19106_Symp_1_head.pdf

[16] Chapman, C. \& Ward, S. (1997). Project Risk Management - Processes, Techniques and Insights; John Wiley \& Sons Ltd: England, 1997, pp. 9-12.

[17] Hallikas, J.; Karvonen, I.; Pulkkinen, U.; Virolainen, V.-M. \& Tuominen, M. (2004). Risk management processes in supplier networks. Int. J. Production Economics 90, 2004, pp. 47-58, DOI:10.1016/j.ijpe.2004.02.007.

[18] Elkington, P. \& Smallman, C. (2002). Managing risks: a case study from the utilities sector. International Journal of Project Management 2002, No. 20, pp. 49-57, PII: S0263-7863(00)00034-X.

[19] Kalra, J. (2005). Medical errors: Impact on clinical laboratories and other critical areas. Clinical Biochemistry 2005, Vol. 37, No. 12, pp. 1052-1062, DOI: https://doi.org/10.1016/j.clinbiochem.2004.08.009.

[20] Lima-Oliveira, G.; Volanski, W.; Lippi, G.; Pichth, G. \& Guidi, G. C. (2017). Pre-analytical phase management: a review of the procedures from patient preparation to laboratory analysis. Scandinavian Journal of Clinical and Laboratory Investigation 2017, Vol. 77, No. 3, pp. 153-163, DOI: 1080/00365513.2017.1295317.

[21] Plebani, M.; Ceriotti, F.; Messeri, G.; Ottomano, C.; Pansini, N. \& Bonini, P. (2006). Laboratory network of excellence: enhancing patient safety and service effectiveness. Clin Chem Lab Med 2006, Vol. 44, No. 2, pp. 150160, DOI: 10.1515/CCLM.2006.028.

[22] Carraro, P. \& Plebani, M. (2007). Errors in a Stat Laboratory: Types and Frequencies 10 Years Later. Clinical Chemistry 2007, Vol. 53, No. 7, pp. 1338-1342, DOI: 10.1373/clinchem.2007.088344.

[23] Rin, D. G. (2009). Pre-analytical workstations: A tool for reducing laboratory errors. Clinica Chimica Acta 2009, Vol. 404, No. 1, pp. 68-74, DOI: https://doi.org/10.1016/j.cca.2009.03.024.

[24] International Organization for Standardization. ISO17025: General requirements for the competence of testing and calibration laboratories. ISO, Geneva, Switzerland. 2018.

[25] Plebani, M. (2006). Errors in clinical laboratories or errors in laboratory medicine? Clinical Chemistry and Laboratory Medicine (CCLM) 2006, Vol. 44, No. 6, pp. 750-759, DOI: https://doi.org/10.1515/CCLM.2006.123.

[26] Piton, A. (2008). Risk-based assessment applied to QA GLP audits: how to fulfill regulatory requirements while making the best use of our common sense, knowledge, talents, and resources?. Ann Ist Super Sanita 2008, Vol. 44, No. 4, pp. 379-384, Available from: https://www.ncbi.nlm.nih.gov/pubmed/19352000.

[27] Lippi, G.; Simundic, A.-M. \& Mattiuzzi, C. (2010). Overview on patient safety in healthcare and laboratory diagnostics. The journal of Croatian Society of Medical Biochemistry and Laboratory Medicine 2010, Vol. 20, No.2, pp. 131-143, DOI: http://dx.doi.org/10.11613/BM.2010.015.

[28] Eliza, R. D. \& Minodora, D. (2015). Risk Management in Clinical Laboratory: from Theory. Acta Medica Marisiensis 2015, Vol. 61, No. 4, pp. 372-377, DOI: 10.1515/amma-2015-0086. 